\title{
Computer Assisted Examination of Infrared and Near Infrared Spectra to Assess Structural and Molecular Changes in Biological Samples Exposed to Pollutants: A Case of Study
}

\author{
Mauro Mecozzi ${ }^{1, *}$ and Elena Sturchio ${ }^{2}$ \\ 1 Laboratory of Chemometrics and Environmental Applications, ISPRA, Via di Castel Romano 100, \\ 00128 Rome, Italy \\ 2 Italian Workers' Compensation Authority (INAIL), Department of Technological Innovation, \\ Safety Plants and Products and Anthropic Settlements (DIT), Via Roberto Ferruzzi 38/40, 00143 Rome, \\ Italy; e.sturchio@inail.it \\ * Correspondence: mauro.mecozzi@isprambiente.it or mauromecozzi2004@libero.it; Tel.: +39-6-5007-3287
}

Academic Editors: Carosena Meola and Gonzalo Pajares Martinsanz

Received: 14 October 2016; Accepted: 8 February 2017; Published: 16 February 2017

\begin{abstract}
We present a computer assisted method for the examination of the structural changes present in the probe organism Vicia faba exposed to inorganic arsenic, detected by means of Fourier transform infrared (FTIR) and Fourier transform near infrared (FTNIR) spectroscopy. Like the common ecotoxicological tests, the method is based on the comparison among control and exposed sample spectra of the organisms to detect structural changes caused by pollutants. Using FTIR spectroscopy, we measured and plotted the spectral changes related to the unsaturated to saturated lipid ratio changes (USL), the lipid to protein ratio changes (LPR), fatty and ester fatty acid content changes (FA), protein oxidation (PO) and denaturation, and DNA and RNA changes (DNA-RNA). Using FTNIR spectroscopy, we measured two spectral ranges that belonged to hydrogen bond interactions and aliphatic lipid chains called IntHCONH and Met1overt, respectively. The FTIR results showed that As modified the DNA-RNA ratio and also caused partial protein denaturation in the Vicia faba samples. The FTNIR results supported the FTIR results. The main advantage of the proposed computational method is that it does not require a skilled infrared or near infrared operator, lending support to conventional studies performed by toxicological testing.
\end{abstract}

Keywords: FTIR spectroscopy; FTNIR spectroscopy; computer analysis; toxic effect of As; structural changes in organisms

\section{Introduction}

Modern ecotoxicology is focused on the study of the interactions among organisms and pollutants with special emphasis on the comprehension of their biological response to pollutant exposures. In these fields of study, novel techniques based on vibrational spectroscopy such as Fourier transform infrared (FTIR) and Fourier near infrared (FTNIR) have been proposed because the biomolecules of the living organisms consist of polysaccharides, proteins, and lipids, molecules that have significant FTIR and FTNIR absorptions [1]. Table 1 reports the list of the most significant FTIR bands of the biomolecules present in Vicia faba roots.

When the living cells are exposed to pollutants, the toxic effect causes structural changes in the biomolecules depending on their interaction with the pollutants [1-6]. Using vibrational spectroscopic techniques such as FTIR and FTNIR, these changes can be visualized by means of band shifts, band shape, and peak intensity (both increase or decrease) changes. Then, the visual comparison among 
the control and exposed samples (Figures 1 and 2), such as a common toxicological and cytotoxic test, becomes a tool for identifying the typical structural changes in the exposed organism.

Table 1. List of the most significant infrared (FTIR) bands and related functional groups assigned for Vicia faba samples. The “*" bands are evidenced by means of second derivative spectroscopy.

\begin{tabular}{|c|c|}
\hline Wavenumber $\mathrm{cm}^{-1}$ & Functional Group \\
\hline $3350-3450$ & $\mathrm{OH}$ of carbohydrates, proteins, and polyphenols \\
\hline $3200-3250$ & $\mathrm{NH}_{2}$ aminoacidic group \\
\hline $3010-3020$ & $\mathrm{CH}$ alkene group \\
\hline $3020-3060$ & $\mathrm{CH}$ of aromatic ring \\
\hline $2850-2950$ & $\mathrm{CH}$ and $\mathrm{CH}_{2}$ aliphatic stretching group \\
\hline $2100-2500$ & $\mathrm{C}=\mathrm{C}$ conjugated and $\mathrm{C} \equiv \mathrm{C}$ \\
\hline $1730-1740$ & $\mathrm{C}=\mathrm{O}$ ester fatty acid group \\
\hline $1700-1715$ & $\mathrm{C}=\mathrm{O}$ fatty acid group \\
\hline $1620-1670$ & $\mathrm{C}=\mathrm{O}$ Amide $\mathrm{I}$ band \\
\hline 1670 * & beta turns Amide I band \\
\hline 1650 * & alpha helix Amide I band \\
\hline 1635 * & beta sheet Amide I band \\
\hline $1625-1630$ * & random coil Amide I band (i.e., denaturation of proteins) \\
\hline $1540-1550$ & C-N Amide II band \\
\hline 1510 * & Lignin skeletal band (aromatic) \\
\hline $1400-1460$ & stretching $-\mathrm{C}=\mathrm{O}$ inorganic carbonate \\
\hline $1350-1440$ & $\mathrm{CH}$ and $\mathrm{CH}_{2}$ aliphatic bending group \\
\hline $1240-1340$ & $\mathrm{C}-\mathrm{N}$ Amide III band \\
\hline $1120-1160$ & $\mathrm{C}-\mathrm{O}-\mathrm{C}$ polysaccharide and DNA and RNA backbones \\
\hline $1085-1080$ & $\mathrm{P}=\mathrm{O}$ phospholipids in DNA and RNA \\
\hline $1080-1060$ & $\mathrm{C}-\mathrm{O}$ carbohydrates in DNA and RNA backbones \\
\hline $900-800$ & $\mathrm{C}=\mathrm{C}, \mathrm{C}=\mathrm{N}, \mathrm{C}-\mathrm{H}$ in ring structure, DNA and RNA backbones \\
\hline
\end{tabular}

FTNIR spectroscopy generally has a lower information power than FTIR spectroscopy, because the absorptions of the functional groups are less intense (two orders of magnitude at least) than the corresponding absorptions of the same functional groups in the infrared region [7].

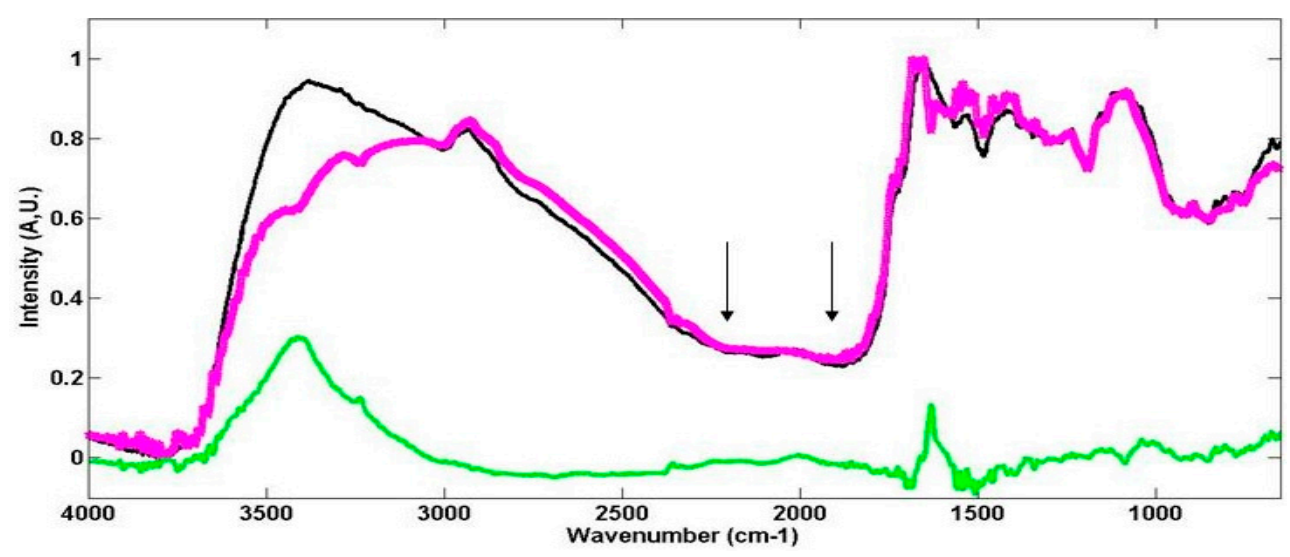

Figure 1. Example of control (black), exposed (purple), and difference (green) FTIR spectra of Vicia faba samples treated with $30 \mathrm{~g} \mathrm{~L}^{-1}$ As. The negative values observed for the difference spectrum in the range between 3100 and $1400 \mathrm{~cm}^{-1}$ show a reduction of the molecular absorptions in the exposed samples with respect to the control sample. The two black arrows show the range where a flat water band could be observed in the case of a non-efficient lyophilisation. 
However, FTNIR spectroscopy has some advantages with respect to FTIR spectroscopy. In fact, the absorptions of $-\mathrm{OH}$ (carbohydrate, protein, and lipid) and -NH (protein) groups are better resolved than those in the FTIR region and the hydrogen bond interactions cause larger band shifts than those observed in the FTIR region, making their interpretation easier [7]. This makes FTNIR spectroscopy reliable for ecotoxicological studies as well, because it provides complementary information to that obtained by FTIR spectroscopy $[8,9]$.

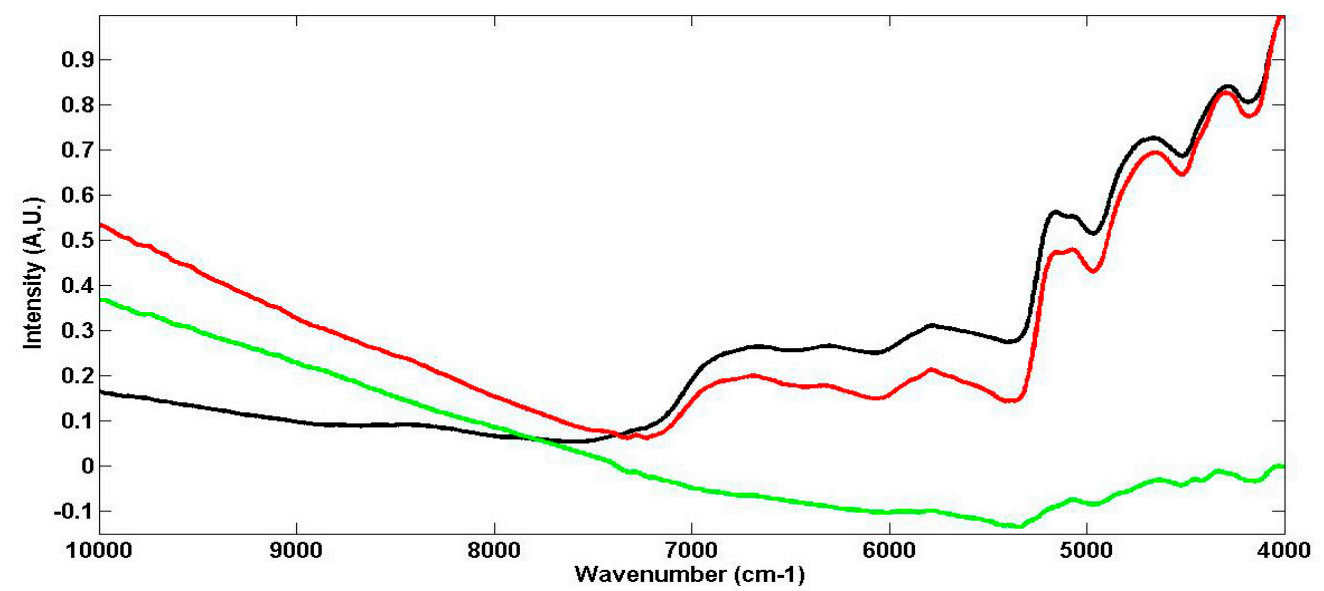

Figure 2. Example of control (black), exposed (red), and difference (green) near infrared FTNIR spectra for a Vicia faba sample treated with $20 \mathrm{~g} \cdot \mathrm{L}^{-1}$ As. The negative values observed in the range between 7500 and $4000 \mathrm{~cm}^{-1}$ of the difference spectrum show a reduction of the molecular absorptions in the exposed samples with respect to the control sample.

Figure 2 reports an example of the comparison between the FTNIR spectra of the control and As exposed Vicia faba samples, while Table 2 reports the detailed list of the near infrared bands.

However, the FTIR and FTNIR spectra such as those in Figures 1 and 2 are characterized by the presence of several bands and the interpretation of the structural changes caused by a pollutant exposure is not an easy task. In fact, a recent review describing the use of FTIR spectroscopy to investigate physiological cell states underlines the complex aspects of their interpretation, because the extraction of information about content and structure in biological systems requires skilled operators and sometimes specific tools such as chemometric methods [10].

Table 2. List of the most significant FTNIR bands and related functional groups assigned for the Vicia faba samples.

\begin{tabular}{cc}
\hline Wavelength $\left(\mathbf{c m}^{-\mathbf{1}}\right)$ & Functional Group \\
\hline $8400-8800$ & $-\mathrm{CH}$ and $-\mathrm{CH}_{2}$ second overtone aliphatic chains \\
$6600-6900$ & $-\mathrm{OH}$ first overtone proteins and lipids \\
$6500-6600$ & $-\mathrm{NH}_{2}$ amino acid first overtone \\
$5100-5200$ & Combination Amide I and $-\mathrm{OH}$ proteins \\
$4800-5000$ & Combination $-\mathrm{OH}$ and Amide II proteins \\
$4200-4800$ & Combination $-\mathrm{NH}_{2},-\mathrm{CH}, \mathrm{C}-\mathrm{C}$, and $-\mathrm{OH}$ \\
\hline
\end{tabular}

With the aim of making the interpretation of FTIR and FTNIR spectra of biological samples submitted for toxicological testing easier, we present a digital approach which does not require skilled knowledge for the interpretation of FTIR and FTNIR spectra. This method is presented and discussed for the exposure of Vicia faba roots to inorganic As. 


\section{Materials and Methods}

\subsection{Sample Collection and Preparation for FTIR and FTNIR Spectroscopic Analysis}

Vicia faba was grown in differentially polluted soils. Vicia faba seeds were sowed in $250 \mathrm{~g}$ quartz sand soil in aluminum basins. Each basin, containing 25 seeds, was treated with $40 \mathrm{~mL}$ sodium arsenate dibasic heptahydrate and incubated in a climatic chamber (at $21^{\circ} \mathrm{C}$ and $60 \%$ relative humidity) for 5 days to enable germination. Seeds were grown in a quartz sand soil basin irrigated with $40 \mathrm{~mL}$ of water. Irrigation with water only was used as a negative control. All of the experiments were repeated three times in June 2013 and three times in July 2013. Concentrations of As in the irrigation water were selected at 10 and $20 \mathrm{~g} \cdot \mathrm{L}^{-1}$ for the June exposure and at 20 and $30 \mathrm{~g} \cdot \mathrm{L}^{-1}$ for the July exposure; the range was selected because at lower concentration, no one molecular effect was detected whereas at higher concentrations there was the inhibition of growth. More details concerning the preparation of Vicia faba samples are reported in a previous study [6].

\subsection{Acquisition of FTIR and FTNIR Spectra of Vicia Faba Samples}

FTIR and FTNIR spectra were collected for the same subsamples previously described. FTIR spectra were collected by a Nicolet single beam spectrophotometer mod. IS50 (Waltham, MA, USA), equipped with a diamond crystal accessory. The spectrum of the diamond crystal was considered as spectroscopic background. For Vicia faba samples, the lyophilized powder of the samples was placed directly on the crystal.

Spectral acquisition was performed in the $650-4000 \mathrm{~cm}^{-1}$ range with $4 \mathrm{~cm}^{-1}$ resolution, after 100 scans, using the cosine function as apodization. Each FTIR spectrum was baseline corrected using the so called selection point method [11] available on several FTIR and FTNIR instruments. Given a spectrum such as the plot below (Figure 3), by means of the graphical user interface we selected some points in the plot where the linear curves are identified.

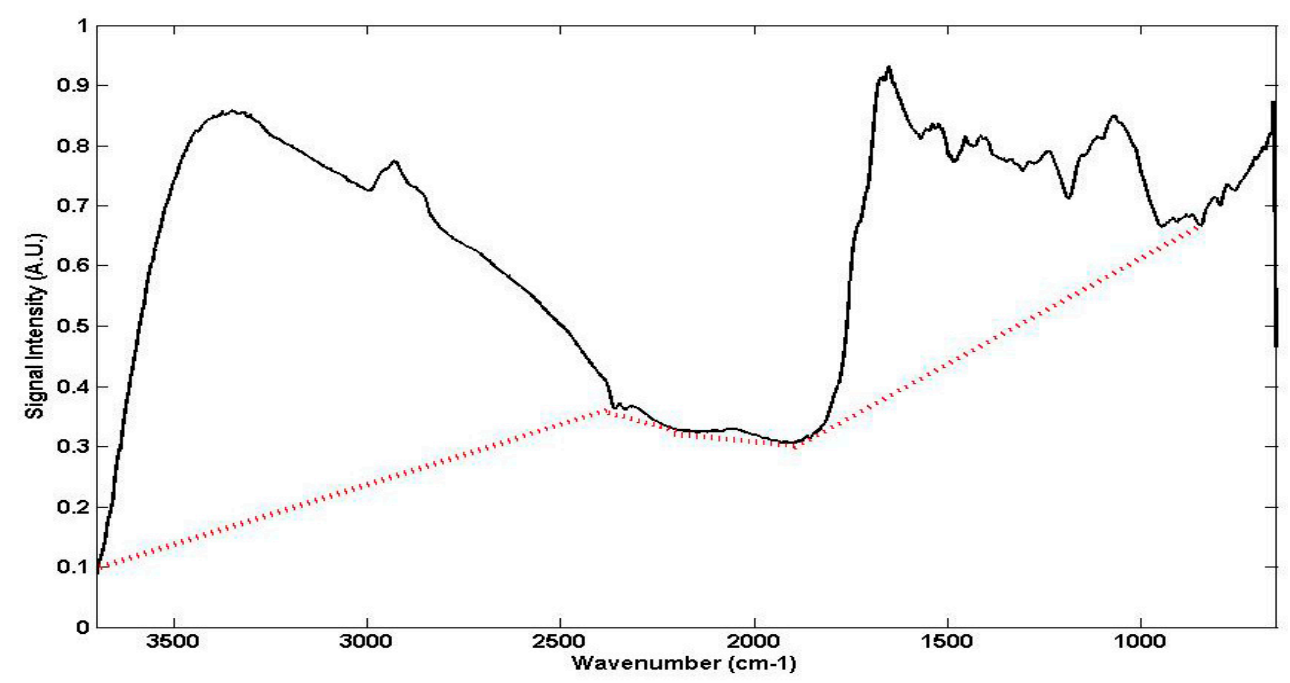

Figure 3. Example of the selection point method application for a spectrum to draw line curves.

Then the areas under the straight lines are subtracted from the original spectral signals to obtain the following baseline drift corrected spectrum (Figure 4). 


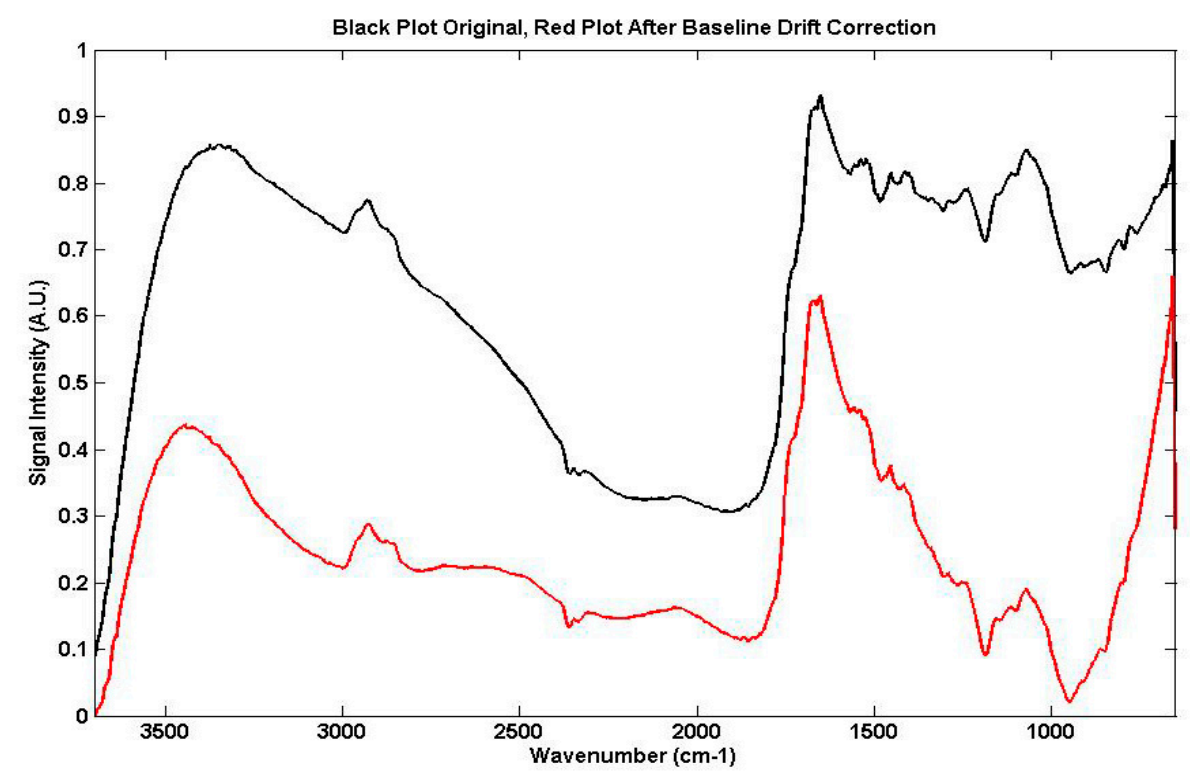

Figure 4. Example of a spectrum before (black) and after baseline drift correction (red) using the selection point method.

After baseline drift correction, we submitted the FTIR and FTNIR spectra to an 11 point smoothing filter to reduce noise and then enhance the signal-to-noise ratio according to the efficient smoothing and differentiation technique for analytical signals called the Savitzki Golay filters [11,12]. It is based on the convolution of the original signals by an appropriate smoothing (i.e., polynomial) filter function " $f$ " according to

$$
\begin{gathered}
j=m \\
X^{\prime} i=\sum f j X(i+j) i=1,2,3 \ldots \ldots, n \\
j=-m
\end{gathered}
$$

where $X$ is the n-point absorption signal file, $X^{\prime}$ is the smoothed signal file, and $m$ is the number of the filtering points. For instance, in the case of a FTIR spectrum in this study, the application of an 11 point filter means that $m=5$, so that each final $X^{\prime} i$ smoothed signal is determined by taking into account the previous five $X j$ values, the $X i$ value, and the next five $X j$ values. With respect to a conventional smoothing filter such as the moving window filter, where

$$
\begin{gathered}
j=m \\
X^{\prime} i=1 /(2 m+1) \sum X(i+j) i=1,2,3 \ldots \ldots, n \\
j=-m
\end{gathered}
$$

the presence of the $f$-function filter allows a very reliable restoration of the signal files, avoiding peak distortions $[11,12]$. These two references also give practical examples of this smoothing filter utilization. Finally, the spectra were saved as ASCII files for further digital elaborations.

The absence of residual water after lyophilisation was tested by the negligible presence of the flat water band, ranging between 1900 and $2500 \mathrm{~cm}^{-1}$ (Figure 1). For the examination of the results we considered the average spectrum of three spectral subsamples for each As concentration.

FTNIR spectra were collected in diffuse reflectance (DRIFT) mode using a Jasco single beam spectrophotometer mod. 420 (Jasco Europe Srl, Milano, Italy), equipped with an EasyDiff (Pike Technology, Madison, WI, USA) accessory. The powder of lyophilized Vicia faba samples (between 10 and $20 \mathrm{mg}$ ) were placed in a steel cup. The spectra were collected in the 10,000 to $4000 \mathrm{~cm}^{-1}$ 
range at spectral resolution $4 \mathrm{~cm}^{-1}$ after 500 scans, using the cosine function as apodization. For FTNIR measurements, ultrapure dried $\mathrm{KBr}$ was used for spectral background. Similar to the FTIR spectra, FTNIR spectra were baseline corrected, submitted to an 11 point smoothing filter and like FTIR spectroscopy, the average of three replicated spectral subsamples were considered. FTNIR spectra were also saved as ASCII files.

\subsection{Basic Theory of the Proposed Digital Examination of FTIR and FTNIR Spectra}

\subsubsection{The Examination of Digitised FTIR Spectra}

The digital approach for spectral examinations consists of a routine in the Matlab (Mathworks Inc., Natik, IL, USA) language which retrieves spectra saved as ASCII files. The Matlab routine performs the examination of FTIR spectra in four separated steps. In the first step, the control and the exposed spectral samples are normalized to make them independent of the amount of sample used for spectral acquisition [11]. The applied normalization method works on the $n-y_{i}$ series of signal intensities of each spectrum identifying the maximum and the minimum values of the signal series. Then all the $\mathrm{y}_{\mathrm{i}}$ values are re-determined by subtracting the minimum value and dividing all the values by the differences between the maximum and minimum values. After this type of normalization, all the spectra (FTIR and FTNIR) have absorptions ranging between 0 and 1.

In the second step, the control and exposed samples are preliminarily plotted jointly to evidence the spectral difference (i.e., quantitative and structural changes) in the same map (please see the example of FTIR spectra in Figure 1).

In the third step, the spectral ranges of DNA and RNA, Amide I and Amide II, and lipids are plotted to give a detailed visualization of the structural changes caused by As (Figure 5). The spectral ranges for detecting the structural changes of all of the molecular groups of DNA, RNA, lipids, carbohydrates, and proteins can be retrieved by means of the most significant FTIR (Table 1).
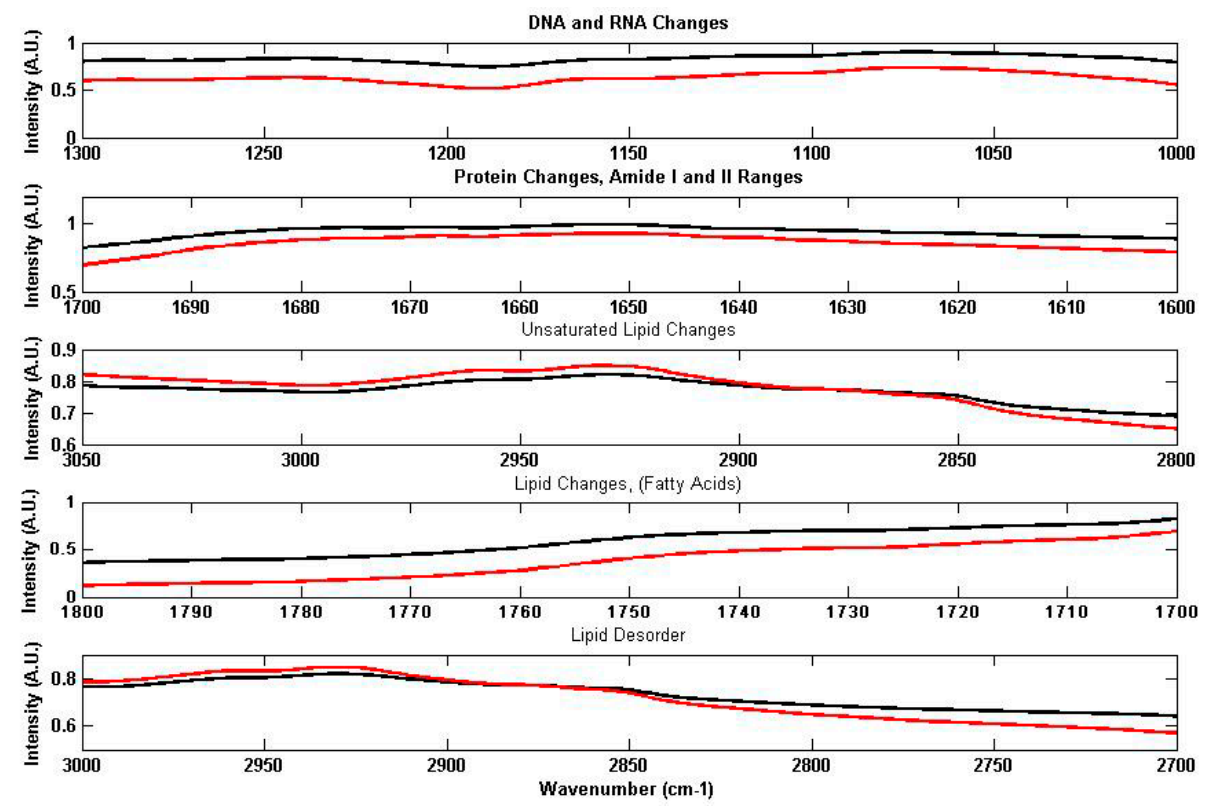

Figure 5. Visualization of the comparison between the control (black) and exposed (red) As (10 g. $\mathrm{L}^{-1}$ ) sample in the FTIR spectral range corresponding to the absorptions of the DNA and RNA region; proteins; unsaturated lipids; fatty acids; and lipid disorder. The spectral ranges are reported starting from the top to the bottom plot.

In the fourth step, by means of the digitized examination of the FTIR spectra we determine the four fundamental parameters selected to detect structural changes arising from the As treatment. 
These parameters are the DNA and RNA area ratio (DNA-RNA), protein oxidation (PO), unsaturated to saturated lipid ratio (USL), and fatty acid area ratio (FA). All these parameters are determined as relative percent changes of the exposed sample band vs. the control sample band area, showing relative reduced or increased signal intensities.

Let us make a numerical example, regarding plot A of Figure 5. DNA and RNA bands are located in the 1300 to $1000 \mathrm{~cm}^{-1}$ range. Firstly, the routine measures the integral of the spectral range, then the two integrals (i.e., control and exposed samples) in the selected range are considered to calculate the area ratio. The selection of the band area instead of the peak height is always suggested because it is more representative and accurate for describing the structural properties and changes of the molecules such as polar and non-polar interactions $[5,10]$.

The PO parameter needs a separate evaluation because it is determined by means of the change ratios in two different spectral ranges, the Amide II range between 1520 and $1580 \mathrm{~cm}^{-1}$ and the range of Amide I between 1580 and $1700 \mathrm{~cm}^{-1}$ [1,5]. Protein oxidation in living cells produces the formation of molecules called non-protein molecules, where the $-\mathrm{C}=\mathrm{O}$ group has infrared absorptions, placed at higher wavenumbers (1700 and $1750 \mathrm{~cm}^{-1}$ ) with respect to the protein $-\mathrm{C}=\mathrm{O}$ group, whereas the absorption of the Amide II band results unchanged [13]. This determines that a positive PO value (i.e., higher in the exposed sample than in the control sample) suggests the presence of protein oxidation and/or depletion [5,14]. A lower or an unchanged PO value with respect to the control sample points out a generic variation of the secondary protein structure without specifying the presence of protein oxidation. This is the case of protein denaturation (please see Section 4.1.2.).

After uploading the control and exposed sample spectral files, the time taken by the computer to perform the analysis is only a few seconds.

\subsubsection{The Examination of Digitised FTNIR Spectra}

The Matlab routine for FTNIR spectroscopy consists of three steps. The first two steps (i.e., normalization and plot of the whole FTNIR spectra) are the same as those described for FTIR spectroscopy. In the third step the routine plots and measures two specific parameters (i.e., with the control to sample ratio area). The first parameter measured by FTNIR spectroscopy is the ratio between the control and exposed sample of the first overtone band of the methyl group in aliphatic chains (MET1overt in the 6000 to $5600 \mathrm{~cm}^{-1}$ range. This band is the marker of specific alterations in living cells [15]. The second parameter belongs to the combination band between 5300 and $4900 \mathrm{~cm}^{-1}$ (IntOHCONH), related to both the inter and intra molecular hydrogen bond interactions among the Amide I and Amide II bands which characterize the secondary protein structure [8]. The spectral ranges are selected according to Table 2, also taking into account that, as already reported, they show the most significant spectral changes.

\subsection{Chemical Reagents}

All the chemicals (water, solvents, and As) were of analytical reagent grade.

\section{Results}

\subsection{Conventional Interpretation of FTIR and FTNIR Spectra for Living Organisms}

\subsubsection{FTIR Spectroscopy}

The absorption bands in the ranges between 3050 and $3000 \mathrm{~cm}^{-1}$ and between 2950 and $2800 \mathrm{~cm}^{-1}$ belong to the $-\mathrm{CH}$ and $-\mathrm{CH}_{2}$ groups of unsaturated and saturated aliphatic chains of lipids, respectively $[16,17]$, though there is also a contribution from the aliphatic chains of proteins. The absorption ratio of these two ranges can be used to estimate the changes of the unsaturated to saturated lipid ratio (USL), because it is the marker of lipid oxidation [17]. Lipid oxidation occurs when cells are submitted to stress conditions which affect the dynamic properties of their membranes $[18,19]$. 
Moreover, the modified shape of the $-\mathrm{CH}_{2}$ aliphatic chains in the 2800 to $3050 \mathrm{~cm}^{-1}$ range can also estimate the increased lipid disorder, another useful marker of lipid alterations in the membrane dynamics [18-20].

The bands in the 1750 to $1700 \mathrm{~cm}^{-1}$ range belong to the $-\mathrm{C}=\mathrm{O}$ carbonyl group of fatty and ester fatty acids [1]. The changes of intensities and/or band shapes in this range suggest the presence of lipid oxidation structural changes, related to the changes of the USL ratio previously described [21]. Therefore, the measurements of the ratio band intensities in the 1750 to $1700 \mathrm{~cm}^{-1}$ range between the control and exposed samples, called FA, is an overview of the structural changes in fatty acids. In fact, lipid oxidation, which is more reasonably a lipid peroxidation [22], produces increased carbonyl compound contents [23] that modify the lipid to protein ratio (i.e., the LPR value). This parameter is easily measurable by means of FTIR spectroscopy [20].

The two main bands in the 1700 to $1520 \mathrm{~cm}^{-1}$ range belong to the so-called Amide I and Amide II bands of the $\mathrm{HN}-\mathrm{C}=\mathrm{O}$ peptidic group of proteins [1]. This spectral range has plenty of information about protein structures [24]. By determining the second derivative of the FTIR spectra in the 1700 to $1620 \mathrm{~cm}^{-1}$ sub-range, the changes in the secondary protein structures involving alpha helix, beta sheet, beta turn, and random coil transitions can also be detected [5,14,25-28] Moreover, the changes of the ratio between the $1580-1520 \mathrm{~cm}^{-1}$ and the $1700-1580 \mathrm{~cm}^{-1}$ (PO) sub-ranges evidence protein depletion and oxidation $[3,14,28,29]$. The fatty acid range between 1700 and $1750 \mathrm{~cm}^{-1}$ (already described), when joined to the 1700 to $1620 \mathrm{~cm}^{-1}$ Amide I range of proteins, is also used to determine the lipid to protein ratio (LPR) which is another marker of protein oxidation [20,21].

The bands ranging between 1250 and $1050 \mathrm{~cm}^{-1}$ belong to the $-\mathrm{CO}$ (i.e., backbone carbohydrates) and $\mathrm{P}=\mathrm{O}$ groups of DNA and RNA molecules and of phospholipids, respectively $[2,3,6,21]$.

\subsubsection{FTNIR Spectra}

FTNIR bands are less numerous than those of FTIR spectra as shown by Figure 2 and Table 2. However, the structural changes evidenced by FTNIR spectroscopy gives us peculiar structural information. The MET1overt parameter measured by comparing the 6000 and $5600 \mathrm{~cm}^{-1}$ (first overtone of aliphatic chains) absorptions of the control and exposed sample, is linked to the re-orientation of lipids called lipid disorder [15], already described by means of FTIR spectra. Changes in hydrogen bond interactions (i.e., the IntHCONH parameter), measured as the ratio in the 5300 to $4900 \mathrm{~cm}^{-1}$ range between the control and exposed sample, describes the interaction among $-\mathrm{C}=\mathrm{O}$ and $-\mathrm{NH}$ groups of proteins, linked to inter and intra hydrogen bond changes of proteins $[8,9]$.

\section{Discussion}

\subsection{As Effects on Vicia Faba Roots by the Proposed Computer Assisted Method}

Arsenic, selected as an example for the proposed method, has a natural occurrence in the environment, ranked as the 20th most abundant element in the earth's crust. Weathering of rocks converts $\mathrm{As}_{2} \mathrm{~S}_{3}$ to $\mathrm{As}_{2} \mathrm{O}_{3}$ which enters the food chain by dissolution in groundwater [30]. Though As also has recognized anti-cancer properties [31,32], it produces a variety of health problems such as immunologic, genotoxic, mutagenetic, and carcinogenic effects [30]. For these reasons, its effects on living organisms are currently under investigation.

We divide the discussion of As effects on Vicia faba roots into quantitative (reduction and increase) changes and non-specific (i.e., transition) changes.

\subsubsection{Quantitative Changes Detected by FTIR Spectroscopy in Vicia Faba Roots}

The plots of Figure 6 are an example of the results obtained by FTIR spectroscopy for the two different times of As treatment; June (top plot) and July (bottom plot). As exposure in the June samples has a major effect on DNA-RNA changes with essentially a minor relevance for the LPR marker. All the remaining parameters (PO, USL, and FA) show little $(<10 \%)$ or even negligible quantitative changes. 
FTIR also suggests that the effect of As is time dependent. In fact, for the June exposure (Figure 6, upper plot), the DNA-RNA parameter has an increasing trend with a relative variation close to $50 \%$, whereas in the July exposure the DNA-RNA parameter has a decreasing trend, with close to $20 \%$ reduction (Figure 6, bottom plot).
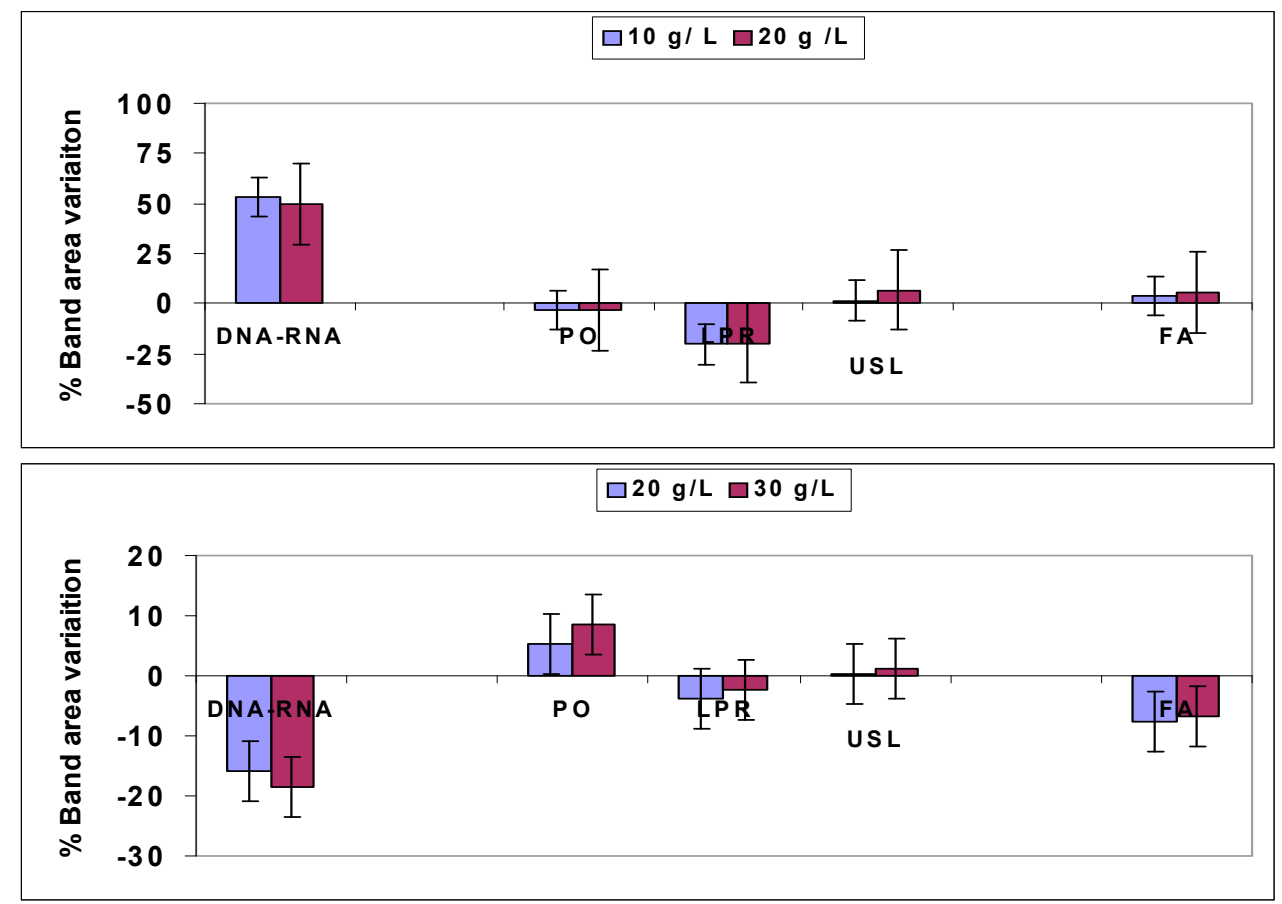

Figure 6. Bar charts of the band area variation with respect to the control sample observed in the FTIR spectra for the As exposure of the June (upper) and July (bottom) plots. Here, the results are the average of the three replicated spectra for each As exposure.

The LPR marker has a $20 \%$ reduction for the June exposure (upper plot) whereas for the July exposure it is almost negligible, close to $5 \%$ for the July exposure (bottom plot). The LPR variations observed for the June treatment suggest that the stress effect caused by As exposure produces an increased lipid disorder. These results are described in better detail in the following section (please see Section 4.1.2).

The remaining markers (PO, USL, and FA) have negligible changes because their variations (increase or decrease) are lower than 10\%, lying in the range of the experimental error.

These results show that the As effects are mainly oriented to produce DNA and RNA changes and to a minor extent, LPR structural changes. These changes depend on the different experimental conditions of As treatment in all cases (i.e., the simple comparison between plots A and B of Figure 5). The FTIR spectra of the other samples confirm the time dependence effect of As.

\subsubsection{Non Specific Structural Changes Detected by FTIR Spectroscopy in Vicia faba Roots}

Figure 7 reports the FTIR spectral range of the Amide I band in derivative mode for the As exposure in June, highly comparable with those in July, showing that the transition changes caused by As in proteins are generally independent of the environmental and time conditions.

In addition, As exposure also caused some molecular re-arrangements involving the two alpha helix bands, which are located at 1646 and $1657 \mathrm{~cm}^{-1}$ for the control sample, whereas in the treated sample we observed only one alpha band, shifted at $1652 \mathrm{~cm}^{-1}$. Since the protein oxidation reactions were almost negligible, as shown by the PO parameter values lower than 10\% (Figure 6, both plots), protein denaturation and unfolding effects are more relevant than oxidative effects. This lets us 
hypothesize that arsenic exposure could essentially cause the partially formation of oligopeptide-metal complexes, according to a mechanism of detoxication already observed in vegetal and animal organisms for $\mathrm{As}[33,34]$ and other pollutants such $\mathrm{Cd}$ and $\mathrm{Pb}[35]$.

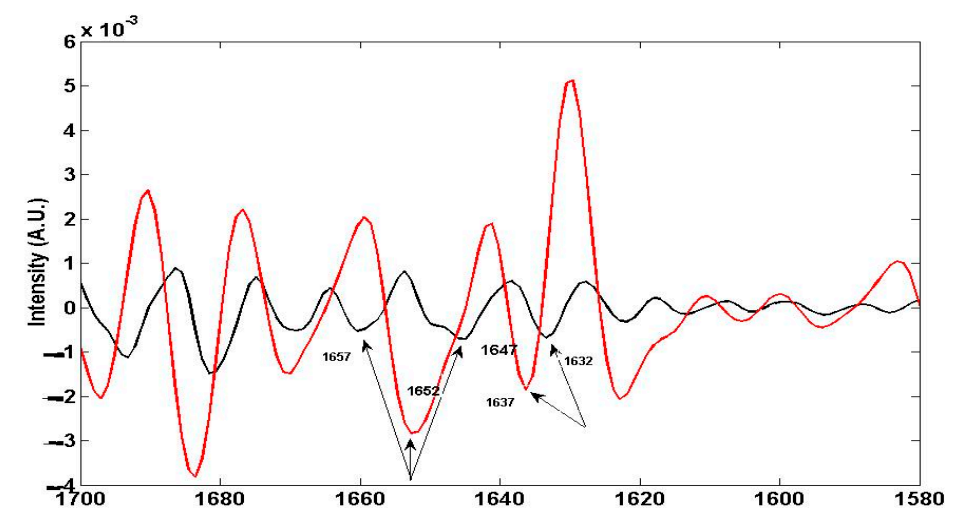

Figure 7. Second derivative FTIR spectra of Amide I bands in Vicia faba roots for the As exposure in June for the same sample of Figure 6. For the July exposure, the FTIR spectra are highly comparable. The black spectrum is the control samples, and the red spectrum is the exposed sample. The arrows show the transitions between the beta sheet $\left(1632 \mathrm{~cm}^{-1}\right)$ with the appearance of random coil $\left(1637 \mathrm{~cm}^{-1}\right)$ and molecular rearrangements within the alpha helix structures in the 1645 to $1660 \mathrm{~cm}^{-1}$ range.

The non-specific effects of As consist of a denaturation of proteins caused by hydrogen bond transitions and protein unfolding, involving the Amide I and Amide II bands of proteins [25-29]. As shown in Figure 7, this transition/denaturation is clearly linked to the modification of the $\beta$-sheet band at $1632 \mathrm{~cm}^{-1}$ present in the control sample and absent in the exposed sample. In fact, in the exposed samples we observe the presence of a new band, the random coil band, present at $1637 \mathrm{~cm}^{-1}$ [25].

Concerning lipid disorder, Figure 8 shows analogous modified shapes of the band placed between 3000 and $2800 \mathrm{~cm}^{-1}$ related to the transitions between the trans and gauche conformations of the aliphatic (i.e., lipid) chains of the $-\mathrm{CH}_{2}$ acyl bands [36,37].

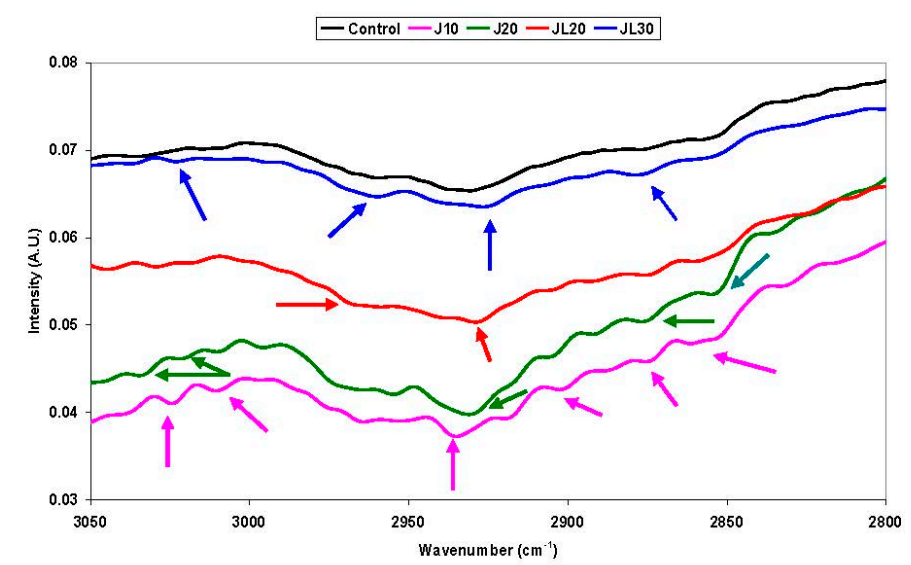

Figure 8. FTIR spectra in second derivative mode showing the increased lipid disorder by the band shifts of the lipid acyl $-\mathrm{CH}_{2}$ bands in samples exposed to As in June and July. This FTIR plot includes all the samples considered in the study. As a qualitative case, the average and standardized spectrum of each sample was considered. "J10" and "J20" are June samples treated with As 10 and $20 \mathrm{~g} \cdot \mathrm{L}^{-1}$, respectively. "JL10" and "JL20" are July samples treated with As 10 and $30 \mathrm{~g} \cdot \mathrm{L}^{-1}$, respectively. The arrows (with the same colour of the sample) show the ranges where the band shape changes are more relevant with respect to the control samples. 


\subsubsection{FTNIR Results}

Figure 9 reports the values of IntHCONH and Metlovert for the same samples shown in Figure 6. The results confirm the time dependent effect, already shown by the FTIR results. For the June samples, we observed the reduction of the IntOHCONH parameter which is due to the combination bands (i.e., hydrogen bonds) among the proteins and polysaccharides (Table 2). These reduction-changes, about $15 \%$, agree with the almost significant variation of the PO parameter measured by FTIR spectroscopy (Figure 6) and with the structural changes, linked to protein denaturation, detected by the second derivative FTIR spectroscopy (Figure 7).
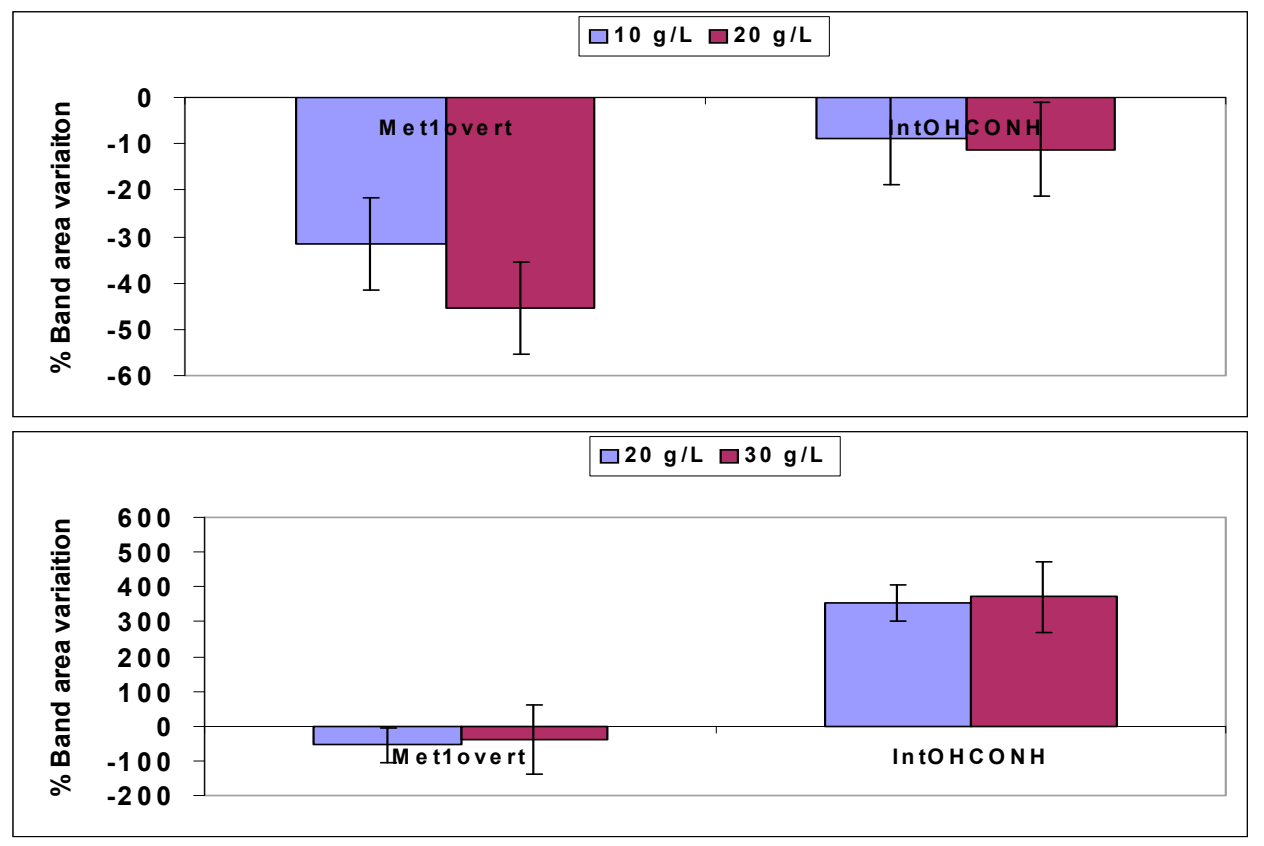

Figure 9. Bar charts of the band area variation with respect to the control sample observed in the FTNIR spectra for the As exposure of the June (upper) and July (bottom) plots. Here, the results are the average of the three replicated spectra for each As exposure.

The Metlovert parameter measured in the 6000 to $5600 \mathrm{~cm}^{-1}$ range belongs to the first overtone bands of the $-\mathrm{CH}_{3}$ and $-\mathrm{CH}_{2}$ groups of aliphatic chains in lipid compounds (Table 2). This change is significant (roughly 50\%), and agrees with the lipid disorder already observed by the FTIR spectroscopy results shown in Figure 5, and in more detail with the acyl bands of Figure 8 describing the lipid disorder induced by the As exposure.

For the July samples, the IntOHCONH value had a great increase (Figure 9). This finding agrees with the protein denaturation detected by the FTIR spectroscopy showing the transitions between the $\beta$-sheet and the random coil structure re-arrangement among the alpha helix structures (Figure 7). The Metlovert parameter related to the lipid structures and contents shows a negative change, close to $50 \%$, comparable with those observed for the June samples. This result shows that FTNIR spectroscopy can support the evidence of lipid disorder effects already shown by the FTIR spectra of Figure 8 .

\section{Conclusions}

The proposed method based on the computer assisted examination of FTIR and FTNIR spectra allows the easy and fast investigation of molecular changes and damages caused in living cells by pollutant exposures. By examining specific cell parameters in the FTIR spectra, molecular modifications related to DNA, RNA, lipid, and protein structures in Vicia faba roots can be detected. In our opinion, this is a peculiar effort to assess specific molecular damages caused by pollutant exposure. However, 
with a reduced contribution, FTNIR spectroscopy is also able to provide supporting data regarding molecular damage in living cells, related to protein denaturation and lipid disorder in Vicia faba roots. Due to its performance, the proposed method for the examination of digitised vibrational spectra can be applied jointly to the common tests of the acute toxicity of pollutants, contributing to a wider knowledge of their effects on living organisms.

Author Contributions: Mauro Mecozzi and Elena Sturchio conceived and designed the study and the experiments jointly. Elena Sturchio took care of the field experiments related to As exposure of Vicia faba and then to their harvest and preparation for spectroscopic (FTIR and FTNIR) analysis. Mauro Mecozzi performed the spectroscopic measurements and developed the computational routines for spectral analysis. The results were discussed together.

Conflicts of Interest: The authors declare no conflict of interest.

\section{References}

1. Stuart, B. Modern Infrared Spectroscopy; John Wiley \& Sons: Chichester, UK, 1996.

2. Yu, C.; Irudayaraj, J. Spectroscopic characterization of microorganisms by Fourier transform infrared microspectroscopy. Biopolymers 2005, 77, 368-377. [CrossRef] [PubMed]

3. Cakmak, G.; Togan, I.; Severcan, F. 17- $\beta$ Estradiol induced compositional, structural and functional changes in rainbow trout liver, revealed by FTIR spectroscopy: A comparative study with nonylphenol. Aquat. Toxicol. 2006, 77, 53-63. [CrossRef] [PubMed]

4. Bezirci, G.; Akkas, S.B.; Karsten Rinke, K.; Feriha Yildirim, F.; Kalaylioglu, Z.; Severcan, F.; Beklioglu, M. Impacts of salinity and fish-exuded kairomone on the survival and macromolecular profile of Daphnia pulex. Ecotoxicology 2012, 21, 601-614. [CrossRef] [PubMed]

5. Palanniappan, P.L.; Vijayasurandam, V. FTIR study of Arsenic induced biochemical changes on the liver tissues of fresh water fingerlings Labeo rohita. Rom. J. Biophys. 2008, 18, 135-144.

6. Boccia, P.; Meconi, C.; Mecozzi, M.; Sturchio, E. Molecular modifications induced by inorganic Arsenic in Vicia faba investigated by FTIR, FTNIR spectroscopy and genotoxicity testing. J. Toxicol. Environ. Health Part A 2013, 76, 281-290. [CrossRef] [PubMed]

7. Ozaki, Y. Near-Infrared spectroscopy-Its versatility in analytical chemistry. Anal. Sci. 2012, 28, 545-563. [CrossRef] [PubMed]

8. Mecozzi, M.; Pietroletti, M.; Tornambè, A. Molecular and structural characteristics in toxic algae cultures of Ostreopsis ovata and Ostreopsis spp. evidenced by FTIR and FTNIR spectroscopy. Spectrochim. Acta Part A 2011, 78, 1572-1580. [CrossRef] [PubMed]

9. Sturchio, E.; Napolitano, P.; Beni, C.; Mecozzi, M. Evaluation of arsenic effects in Vicia faba by FTIR and FTNIR spectroscopy. Glob. NEST J. 2012, 14, 86-92.

10. Wagner, H.; Dunker, S.; Liu, Z.; Wilhelm, C. Subcommunity FTIR-spectroscopy to determine physiological cell states. Curr. Opin. Biotechnol. 2013, 24, 88-94. [CrossRef] [PubMed]

11. Zupan, J. Algorithms for Chemists; John Wiley \& Sons: Chichester, UK, 1989.

12. Savitzky, A.; Golay, M.J.E. Smoothing and differentiation of data by a simplified least squares method. Anal. Chem. 1964, 36, 1627-1639. [CrossRef]

13. Dalle-Donne, I.; Rossi, R.; Giustarini, D.; Milzani, A.; Colombo, R. Protein carbonyl groups as biomarkers of oxidative stress. Clin. Chim. Acta 2003, 329, 23-38. [CrossRef]

14. Mecozzi, M.; Sturchio, E. Effects of essential oil treatments on the secondary protein structure of Vicia faba: A mid-infrared spectroscopic study supported by two-dimensional correlation analysis. Spectrochim. Acta Part A 2015, 137, 90-98. [CrossRef] [PubMed]

15. Kondepati, V.R.; Keese, M.; Mueller, R.; Backhaus, J. Near-infrared spectroscopic detection of human colon diverticulis: A pilot study. Vib. Spectrosc. 2007, 44, 56-61. [CrossRef]

16. Christy, A.A.; Egeberg, P.K. Quantitative determination of saturated and unsaturated fatty acids in edible oils by infrared spectroscopy and chemometrics. Chemom. Int. Lab. Syst. 2006, 82, 130-136. [CrossRef]

17. Bertoluzza, A.; Bottura, G.; Filippetti, P.; Tosi, M.R.; Vasina, M.; Pratella, G.C.; Folchi, A.; Gallerani, G. Vibrational spectroscopy for the evaluation of molecular perturbation indiced in fruit lipids by cold storage. J. Mol. Struct. 1994, 324, 177-188. [CrossRef] 
18. Lee, D.C.; Chapman, D. Infrared spectroscopic studies of biomembranes and model membranes. Biosci. Rep. 1986, 6, 235-245. [CrossRef] [PubMed]

19. Triba, M.N.; Deveaux, P.F.; Warscheawski, D.E. Effects of lipid chain length and unsaturation on bicelles stability. A phosphorous NMR study. Biophys. J. 2006, 91, 1357-1367. [CrossRef] [PubMed]

20. Navarro, S.; Borchman, D.; Bicknell-Brown, E. Lipid-protein ratios by infrared spectroscopy. Anal. Biochem. 1984, 136, 382-389. [CrossRef]

21. Stehfest, K.; Toepel, J.; Wihlhelm, C. The application of micro-FTIR spectroscopy to analyze nutrient stress-related changes in biomass composition of phytoplankton algae. Plant Phys. Biochem. 2005, 43, 717-726. [CrossRef] [PubMed]

22. Raven, J.A.; Ball, L.A.; Beardall, J.; Giordano, M.; Maberly, S.C. Article lacking carbon-concentrating mechanisms. Can. J. Bot. 2005, 83, 879-890. [CrossRef]

23. Soto, P.; Gaete, H.; Hidalgo, M.E. Assessment of catalase activity, lipid peroxidation, chlorophyll-a, and growth rate in the freshwater green algae Pseudokirchneriella subcapata exposed to copper and zinc. Lat. Am. J. Aquat. Res. 2011, 39, 280-285. [CrossRef]

24. Pauling, L.; Corey, R. Configurations of polypeptide chains with favoured orientations around single bonds. Proc. Natl. Acad. Sci. USA 1951, 37, 241-250. [CrossRef] [PubMed]

25. Conti, L.; Grimaldi, P.; Udroiu, I.; Bedini, A.; Giliberti, C.; Giuliani, L.; Palomba, R.; Congiu Castellano, A. Effects induced in cells by ultrasound revealed by ATR-FTIR spectroscopy. Vib. Spectrosc. 2010, 52, 79-84. [CrossRef]

26. Barth, A. Infrared spectroscopy of proteins. Biochim. Biophys. Acta 2007, 1767, 1073-1101. [CrossRef] [PubMed]

27. El Khoury, Y.; Hielscher, R.; Voicescu, M.; Gross, J.; Hellwig, P. On the specificity of the amide VI band for the secondary structure of proteins. Vib. Spectrosc. 2011, 55, 258-266. [CrossRef]

28. Palanniappan, P.L.; Vijayasurandam, V. Fourier transform infrared study of protein secondary structural changes in the muscle of Labeo rohita due to arsenic intoxication. Food Chem. Toxicol. 2008, 46, 3534-3539. [CrossRef] [PubMed]

29. Palanniappan, P.L.; Vijayasurandam, V. The effect of Arsenic exposure on the biochemical and mineral contents of Labeo rohita bones: An FTIR study. Infrared Phys. Technol. 2009, 52, 32-36. [CrossRef]

30. Mandal, B.K.; Suzuki, T.K. Arsenic round the world: A review. Talanta 2002, 58, 201-235. [CrossRef]

31. Yedjou, C.; Thuisseu, L.; Tchounwou, C.; Gomes, M.; Howard, C.; Tchounwou, P. Ascorbic Acid Potentiation of Arsenic Trioxide Anticancer Activity Against Acute Promyelocytic Leukemia. Arch. Drug Inf. 2009, 2, 59-65. [CrossRef] [PubMed]

32. Swindell, E.P.; Hankins, P.L.; Chen, H.; Miodragović, D.U.; O’Hallora, T. Anticancer Activity of Small-Molecule and Nanoparticulate Arsenic(III) Complexes. Inorg. Chem. 2013, 52, 12292-12304. [CrossRef] [PubMed]

33. Zhao, F.J.; McGrath, S.P.; Meharg, A.A. Arsenic as a food chain contaminant: Mechanisms of plant uptake and metabolism and mitigation strategies. Ann. Rev. Plant Biol. 2010, 61, 535-559. [CrossRef] [PubMed]

34. Vithanage, M.; Dabrowska, B.B.; Mukherjee, A.B.; Sandhi, A.; Bhattacharya, P. Arsenic uptake by plants and possible phytoremediation applications: A brief overview. Environ. Chem. Lett. 2012, 10, 217-224. [CrossRef]

35. Aja, M.; Jaya, M.; Vijayakumaran Nair, K.; Joe, I.H. FT-IR spectroscopy as a sentinel technology in earthworm toxicology. Spectrochim. Acta Part A 2014, 120, 534-541. [CrossRef] [PubMed]

36. Szalontai, B.; Nishyama, Y.; Gombos, Z.; Murata, N. Membrane dynamics as seen by Fourier transform infrared spectroscopy in a cyanobacterium, Synechocystis PCC 6803. The effects of lipid unsaturation and the protein-to-lipid ratio. Biochim. Biophys. Acta 2000, 1509, 409-419. [CrossRef]

37. Kóta, Z.; Debreczeny, M.; Szalontai, B. Separable contributions of ordered and disordered lipid fatty acyl chain segments to $-\mathrm{CH}_{2}$ bands in model and biological membranes: A Fourier transform infrared spectroscopic study. Biospectroscopy 1999, 5, 168-178. [CrossRef]

(C) 2017 by the authors; licensee MDPI, Basel, Switzerland. This article is an open access article distributed under the terms and conditions of the Creative Commons Attribution (CC BY) license (http:/ / creativecommons.org/licenses/by/4.0/). 